\title{
As instituições de microcrédito no Brasil: uma perspectiva sobre o fluxo de fundos no setor
}

The institutions of microcredit in Brazil: a perspective on the funds flow industry

Las instituciones del microcrédito en Brasil: una perspectiva sobre la industria de flujo de recursos

\section{Paulo Augusto Ramalho de Souza}

Doutor em Administração na Universidade Municipal de São Caetano do Sul (USCS)

Professor da Faculdade de Administração e Ciências Contábeis da Universidade Federal de Mato Grosso (UFMT)

Endereço: Av. Fernando Corrêa da Costa, no 2367 - Bairro Boa Esperança

CEP: 78060-900 - Cuiabá/MT Brasil

E-mail: pauloramalho@ufmt.br

Telefone: (65) 3615-8519

\section{Maria do Carmo Romeiro}

Doutora em Administração na Universidade de São Paulo (USP)

Professora do Programa de Doutorado em Administração da Universidade Municipal de São Caetano do Sul (USCS)

Endereço: Av. Goiás, n. 3.400 - Bairro Barcelona

CEP: 09550-051 - São Caetano do Sul/SP Brasil

E-mail: mromeiro@uscs.edu.br

Telefone: (11) 42393257

Artigo recebido em 28/06/2016. Revisado por pares em 15/03/2017. Reformulado em 27/08/2017. Recomendado para publicação em 22/09/2017 por Carlos Eduardo Facin Lavarda (Editor-Chefe). Publicado em 31/12/2017. 


\section{Resumo}

As instituições operadoras de microcrédito necessitam ampliar as discussões sobre a configuração do fluxo de fundos no Brasil. Com foco neste fenômeno, esta pesquisa objetivou ampliar as discussões sobre a configuração do fluxo de fundos bem como as instituições ligadas direta ou indiretamente ao ambiente de microfinanças brasileiro. Para tal, foram realizadas entrevistas com 09 atores ligados ao setor (instituições operadoras de microcrédito, associações do setor, fórum latino de microcrédito e bancos de desenvolvimento). Registre-se que o processo de análise dos dados foi realizado com base na técnica de análise de conteúdo, em virtude de sua relação com as características metodológicas da pesquisa. Os resultados destacam a dependência de fundos oriundos de organizações públicas, bancos privados e a existência de uma estrutura que influência na governança das instituições, à qual pode intervir estrategicamente na tomada de decisão e no desempenho organizacional.

Palavras-chave: Fluxo de fundos; Microfinanças; Instituições de microfinanças; Desempenho

\section{Abstract}

The microfinance institutions need to broaden the discussions about the configuration of the flow of funds in Brazil. Focusing on this phenomenon, this research aimed to broaden the discussions about the configuration of the flow of funds as well as institutions directly or indirectly linked to the Brazilian microfinance environment. To that end, interviews were conducted with 09 actors related to the sector (microcredit operators, sector associations, Latin microfinance forum and development banks). It should be noted that the data analysis process was carried out based on the technique of content analysis, due to its relation with the methodological characteristics of the research. The results highlight the reliance on funds from public organizations, private banks and the existence of a structure that influences the governance of institutions, which can intervene strategically in decision making and organizational performance.

Keywords: Flow of funds; Microfinance; Microfinance institutions; Performance

\section{Resumen}

Las instituciones operadoras de microcrédito necesitan ampliar las discusiones sobre la configuración del flujo de fondos en Brasil. Con el foco en este fenómeno, esta investigación objetivó ampliar las discusiones sobre la configuración del flujo de fondos así como las instituciones ligadas directa o indirectamente al ambiente de microfinanzas brasileño. Para ello, se realizaron entrevistas con 09 actores vinculados al sector (instituciones operadoras de microcrédito, asociaciones del sector, foro latino de microcrédito y bancos de desarrollo). Se registra que el proceso de análisis de los datos fue realizado con base en la técnica de análisis de contenido, en virtud de su relación con las características metodológicas de la investigación. Los resultados destacan la dependencia de fondos provenientes de organizaciones públicas, bancos privados y la existencia de una estructura que influye en la gobernanza de las instituciones, a la que puede intervenir estratégicamente en la toma de decisión y en el desempeño organizacional.

Palabras clave: Flujo de recursos; Microfinanzas; Instituciones de microfinanzas; Desempeño

\section{Introdução}

A oferta de crédito no mercado de microfinanças pode ser realizada por qualquer tipo de instituição financeira, de pequeno ou grande porte, seja um banco formal ou informal (em alguns casos evidencia-se a presença de agiotagem neste mercado). 
As instituições de microfinanças formais desenvolvem atividades e uma variedade de serviços, dentre os quais, destacam-se a oferta de microcrédito, poupança, serviços de pagamento, seguros, crédito imobiliário, crédito estudantil e qualquer outro produto financeiro ou serviço, que um banco comercial não oferece aos mutuários pobres no sistema financeiro tradicional (HOQUE; CHISHTY; HALLOWAY, 2011; SOUZA, 2015).

Assim, as Instituições de Microfinanças (IMFs) atuam como elo entre os fundos e os mutuários de microcrédito. Para Aditto, Gan e Nartea (2014) as IMFs têm a função de oferecer a um número crescente de atores pobres um conjunto de serviços financeiros de baixo custo, sem que estes se desloquem de sua comunidade. Para os autores, a ação dessas instituições tem foco no incremento das condições de vida das famílias.

No Brasil, o mercado de microfinanças têm características próprias a serem identificadas, visto que mesmo sendo um dos primeiros países a iniciar as atividades na América latina, na década de 70, não acompanhou desenvolvimento de produtos e serviços de grande parte dos países da região (MIX, 2012).

Indícios sugerem que a incipiente evolução do setor de microfinanças brasileiro pode estar relacionada tanto com a dependência das IMFs de recursos públicos, como pelo alto grau de desenvolvimento do setor de crédito tradicional no país (AL-MAMUN; WAHAB; MAZUMDER, 2014; SOUZA, 2015).

A relação entre as IMFs, fontes de financiamento (doações ou fundos) internas e externas e as demandas relacionadas com a busca por estruturas de gestão racionais, estão entre as mais recorrentes justificativas de pesquisas acerca do setor de microfinanças, segundo um conjunto de autores (MORDUCH, 2000; LATIFE, 2006; CULL et al., 2007; ARMENDARIZ; MORDUCH, 2010; HUSAIN; JIWANI, 2012; SANFELIU; ROYO; CLEMENTE, 2013; DE SOUZA; DA SILVA; DA COSTA, 2017).

Nesta linha, no caso brasileiro o entendimento sobre as características do fluxo de crédito no mercado de microfinanças ainda é incipiente (AUGUSTO DE SOUZA; CARMOROMEIRO; BRESCIANI, 2015). Para tal, esta pesquisa buscou ampliar as discussões sobre a configuração do fluxo de fundos bem como as instituições ligadas direta ou indiretamente ao ambiente de microfinanças brasileiro.

Registre-se que a presente pesquisa é parte integrante de um estudo realizado entre a Universidade Municipal de São Caetano do Sul - São Paulo e a Universidade do Minho Portugal.

\section{Crédito e as Microfinanças no Brasil}

A palavra crédito tem origem na Roma Antiga e provém do latim credere, que significa crer ou conferir confiança. Neste período, o acesso ao crédito era concedido a pessoas com boa índole ou boa "qualidade" perante a sociedade.

As discussões relacionadas com o crédito, conforme Schumpeter (1997, p. 42), estão relacionadas ao desenvolvimento econômico e social, tendo como definição o seguinte:

\footnotetext{
O crédito é essencialmente a criação de poder de compra com o propósito de transferilo ao empresário, mas não simplesmente a transferência de poder de compra existente. A criação de poder de compra caracteriza, em princípio, o método pelo qual o desenvolvimento é levado a cabo num sistema com propriedade privada e divisão do trabalho. Através do crédito, os empresários obtêm acesso à corrente social dos bens antes que tenham adquirido o direito normal a ela. Ele substitui temporariamente, por assim dizer, o próprio direito por uma ficção deste.
} 
O exercício do crédito, conforme explicado por Giancoli (2008), destaca a importância da confiança considerada atributo de qualidade do credor do negócio, em conjunto ao tempo que o tomador necessita para quitar sua obrigação, frente ao acordo firmado. Esse processo se traduz para o autor como a mais pura definição de crédito.

O crédito está relacionado com a operação de recebimento de determinado recurso, por meio da aceitação da obrigação de reembolso futuro deste a determinando ator ou instituição (BESLEY,1995).

A confiança e a fé são os pilares da oferta de crédito para Xavier (2012). O autor destaca que o ato de transferir recursos de uma pessoa para outra é uma crença em valores sociais, que tendem a ponderar e administrar os riscos inseridos na atividade de venda de recursos ao empreendedor.

Dando sequência ao papel sociológico do crédito, Schrickel (1995) destaca que o indivíduo dotado de vontade ou disposição financeira de ceder a um terceiro, por um período temporário um extrato de seu patrimônio na intenção de que, a partir desta relação, o retorno deste recurso seja realizado com algum incremento, é denominado credor.

$\mathrm{Na}$ ótica do tomador, o crédito é um instrumento relevante para viabilizar a intensidade de capital, para compra de insumos, facilitar o processo de produção e o desenvolvimento da atividade produtiva (PEREIRA; FIGUEIREDO; LOUREIRO, 2006; WILBERT et al., 2014).

A relação entre tomadores e ofertadores de crédito, para Vieira, Pinho e Oliveira (2013) pode ser explicada a partir de um agrupamento de regras e normativas, que formam o serviço denominado empréstimo comercial.

O empréstimo comercial é um contrato relativo a um financiamento, por meio do qual é regulado um acordo entre o ofertador (instituição) e o mutuário. Neste, é especificado um conjunto de normas (direitos e deveres mútuos) celebradas entre ambos.

Já o microcrédito é descrito por Barone et al. (2002) como uma concessão de crédito de valor reduzido a micro e pequenos empreendedores informais e microempresas sem acesso ao setor bancário formal, principalmente, por não terem como oferecer garantias reais. É um crédito destinado à produção (capital de giro e investimento) e concedido com o uso de metodologia específica.

Mireles, Mejía e Rodríguez (2014, p. 03) conceitua o microcrédito, por meio de um conjunto de características dos atores e do ambiente, sendo que:

\footnotetext{
Pequenos empréstimos concedidos a pessoas que não têm os pré-requisitos para um banco que concedeu o empréstimo. O microcrédito é uma ferramenta usada em países em desenvolvimento para promover e fortalecer a instalação de novas iniciativas empresariais, sem recursos financeiros que procuram financiamento para um projeto ou empresa, que requeira a taxa de juros é muito baixa para as pessoas a resolver.
}

Corroborando com o discurso da existência de especificidades na oferta de microcrédito De Souza, Da Silva e Da Costa (2017) descreve que as metodologias de oferta de microcrédito, a necessidade dos agentes de crédito se deslocarem ao encontro dos empreendedores e os baixos valores emprestados, são algumas das características do microcrédito no mercado brasileiro.

Tanto os serviços de crédito tradicional, como os de microcrédito estão presentes no sistema financeiro, o qual é configurado por: instituições monetárias, não monetárias e por agentes econômicos individuais ou coletivos, os quais realizam trocas e regulam o fluxo de fundos, como pode ser observado na figura 1 (LOPES, 2013). A governança deste conjunto de instituições financeiras, para o autor, assegura a manutenção de recursos para o investimento em mercados financeiros através da comercialização de produtos que atendam as demandas dos consumidores de crédito. 
Figura 1- Fluxo de Fundos do Mercado de Crédito

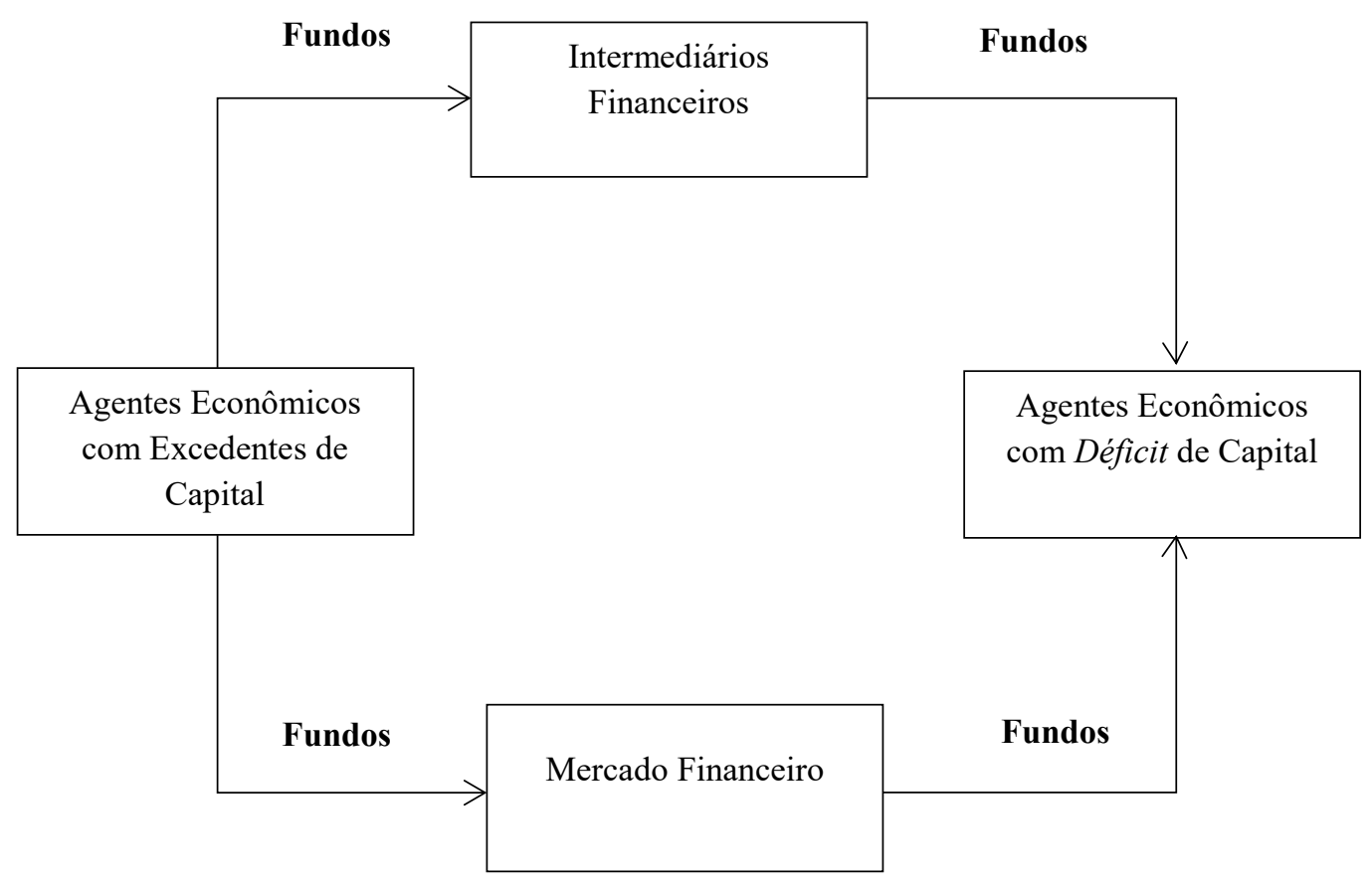

Fonte: Elaborado com base em Lopes (2013).

Com a distribuição de crédito, no contexto deste mercado, as instituições financeiras e os agentes informais desempenham uma relevante função para o setor. Entretanto, a efetividade em suas atuações está relacionada com um conjunto de fatores que vão, por um lado, desde problemas com assimetria de informação, até por outro, com ações de racionalização de custos operacionais.

Cabe ressaltar que a circulação de crédito em determinado país, como no caso do Brasil, é relacionada com a configuração da política de crédito, a qual segundo Wilbert et al. (2014) pode influenciar o consumo de bens e o desenvolvimento de negócios. Registre-se que, o crédito ao consumidor, pode ser considerado um dos maiores segmentos do setor financeiro no Brasil e no mundo (GONÇALVES; GOUVÊA; MANTOVANI, 2013).

Deste modo destaca-se que a configuração do fluxo de fundos pode ser apontada como estratégica para o desenvolvimento da atividade produtiva e para as instituições presentes no mercado de microfinanças brasileiro.

Embora agrupadas simplesmente como "instituições de microfinanças", as organizações que prestam serviços financeiros para os pobres são diversas. Elas variam de organizações não governamentais (ONGs), agências de desenvolvimento rural, bancos públicos e privados, cooperativas de crédito, dentre outros modelos de diferentes tamanhos (ARMENDARIZ; MORDUCH, 2010).

Segundo o Banco Central (2005), no Brasil as IMFs, visam proporcionar acesso facilitado ao crédito para os pequenos empreendimentos, com linhas de crédito popular, enquadradas nas seguintes características:

○ Organizações de Sociedade Civil de Interesse Público (OSCIPs) - São organizações sem fins lucrativos, sua fundação data da aprovação do Ministério da Justiça e são obrigadas a aplicar seu excedente operacional em seu objetivo social. 
○ Sociedades de Crédito ao Microempreendedor - São organizações monitoradas pelo Banco Central, proibidas de desenvolver outras atividades que não sejam relacionadas com o microcrédito, e devem possuir um patrimônio mínimo de 100 mil reais para sua constituição.

○ Organizações Não Governamentais - Organizações que não trabalham necessariamente com crédito e podem oferecer um conjunto com diferentes produtos e serviços. Esta estrutura organizacional não necessita de um limite mínimo para operar.

○ Os Programas Governamentais - São instituídos e gerenciados por meio de leis e normativas dos Estados e Municípios.

- As Cooperativas de Crédito - São serviços, exclusivos, para cooperados restritos a apenas uma modalidade de crédito, frequentemente, voltado para o suporte à atividade produtiva.

Nesta linha, quanto aos serviços financeiros ofertados no setor de microfinanças brasileiro Augusto de Souza, CarmoRomeiro e Bresciani (2015), descrevem que os mesmos são organizados a partir de quatro diferentes grupos: empréstimo individual; antecipação de recebíveis; microcrédito habitacional e grupo solidário. Como pode ser visualizado na figura 2 , a seguir.

Figura 2- Metodologias de Oferta Microcrédito

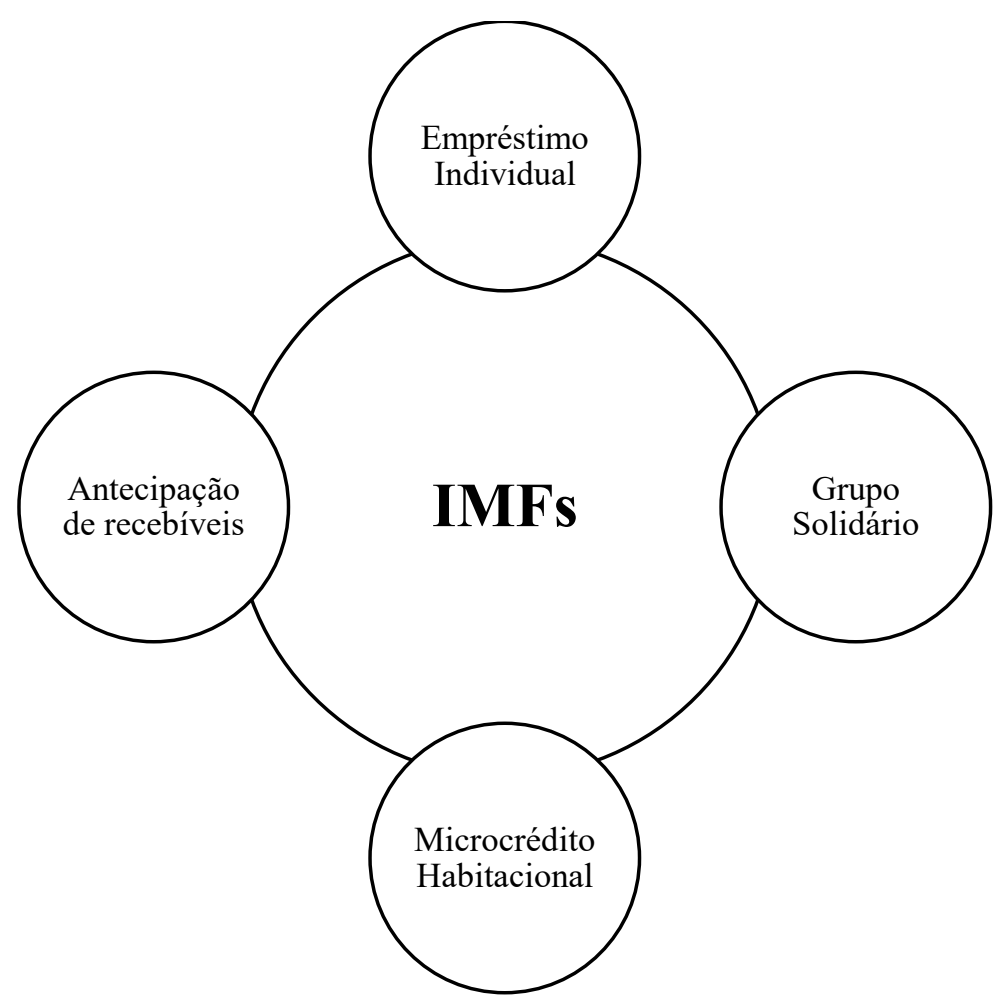

Fonte: Augusto de Souza, CarmoRomeiro e Bresciani (2015, p. 89).

Um relevante exemplo de instituição de microfinanças com uma gama de diferentes modalidades de microcrédito é o Banco Sol, situado na Bolívia. A instituição agrega microcrédito rural, habitacional, educacional, aquisição de veículos, pequenas empresas e empreendedores informais com foco na inclusão social (BANCO SOL, 2015).

Embora, haja inconformidades no setor, as microfinanças são entendidas como um conjunto de serviços ofertados por instituições financeiras públicas ou do terceiro setor para 
agentes individuais de baixa renda ou para microempreendedores (LATIFE, 2006; PEREIRA; MOURÃO, 2012).

\section{Procedimentos Metodológicos}

Os procedimentos metodológicos adotados para esta pesquisa buscaram dar suporte aos objetivos propostos, com o intuito de subsidiar o melhor entendimento do fenômeno do mercado de microcrédito brasileiro. Nesta linha, o foco desta pesquisa teve por base atores relacionados com o ambiente de gestão de IMFs brasileiras.

Dadas as características do fenômeno está pesquisa configura-se com uma abordagem qualitativa com objetivos exploratórios, pois busca extrair e delinear conceitos acerca do fluxo de fundos na visão de gestores de instituições ligadas ao mercado de IMFs brasileiro (VERGARA, 2012). Registre-se que para com o intuito de ilustrar as etapas metodológicas adotas nesta pesquisa a figura 3 .

Figura 3- Delineamento Metodológico da Pesquisa

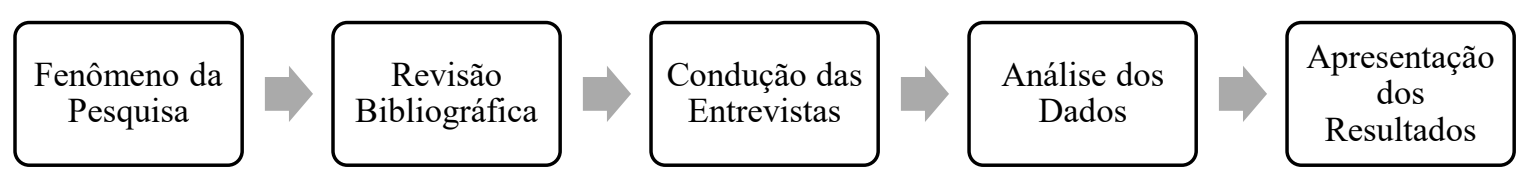

Fonte: Elaborado pelos autores.

As nove entrevistas foram realizadas com atores vinculados a IMFs e instituições que possuíam experiência com a oferta de microcrédito produtivo orientado no Brasil e da América Latina. Os casos da pesquisa foram selecionados intencionalmente, haja vista a busca de atores que possuíam relação direta com o problema da pesquisa.

Foram selecionados bancos públicos, bancos de desenvolvimento, associações do setor, representantes de fóruns internacionais e instituições parceiras, de forma a melhor contemplar o ambiente onde as IMFs estão inseridas, como pode ser ilustrado pelo quadro 1.

Quadro 01- Atores Inferidos na Pesquisa

\begin{tabular}{|c|l|}
\hline $\begin{array}{c}\text { Número de } \\
\text { Entrevistados }\end{array}$ & \multicolumn{1}{c|}{ Instituições } \\
\hline 01 & Fórum Latino Americano e do Caribe de Oferta de Microcrédito Produtivo Orientado \\
\hline 01 & Associação Brasileira de Entidades Operadoras de Microcrédito Produtivo Orientando \\
\hline 02 & Banco de Desenvolvimento Público \\
\hline 05 & IMFs \\
\hline
\end{tabular}

Fonte: Elaborado pelos autores.

A coleta de dados foi realizada por meio de roteiro de entrevista, com a função de auxiliar no aprofundamento das características do fluxo de fundos no setor de microfinanças no Brasil, a partir da visão dos entrevistados.

As entrevistas, conduzidas a partir da pergunta orientadora "Fale o como você entende o fluxo de Fundos/Crédito/Recurso no setor de microfinanças no Brasil?". (O uso das três terminologias "fundos, créditos e recursos" se deu em virtude da necessidade de consolidar as diferentes abordagens que possam personificar o fenômeno do conceito para os entrevistados do setor). 
Registre-se que para a análise dos dados coletados pela pesquisa foi utilizada a técnica de análise de conteúdo, esta técnica segundo Trivinos (1987) deve ser apoiada por referencial teórico preferencialmente relacionado com o problema de pesquisa, dando suporte ao tratamento e apresentação dos resultados.

\section{Análise e Discussão dos Dados}

As constatações iniciais evidenciadas pelo referencial teórico demonstraram a complexidade do fenômeno do fluxo de crédito e das relações entre instituições presentes no mercado de microfinanças brasileiro. Sob essa perspectiva, abordagens metodológicas complementares foram utilizadas objetivando maior efetividade no entendimento dos conceitos e a mensuração de suas relações.

O mercado de microfinanças na América Latina avançou com a ampliação das políticas públicas de inclusão produtiva e combate, como já discutido por Pollinger, Outhwaite e Cordero-Guzmán (2007) e confirmado por Ruscheinsky e Mendizábal (2014).

Em consonância com esse cenário no Brasil (2005), instituiu a configuração da oferta de microcrédito em todo o território nacional, e evidenciou-se como marco regulatório inicial do mercado de microfinanças brasileiro. Ressalta-se que, a partir da configuração de uma estrutura de regulação para o setor no Brasil, o Ministério do Trabalho e Emprego tende a possuir papel de incentivar o acesso às microfinanças por meio de programas de inclusão produtiva.

Para isso, um conjunto de políticas e programas foi desenvolvido, dentre os quais, o PNMPO destaca-se como principal programa de suporte ao microcrédito em atividade pelo MTE, conforme descrevem Augusto de Souza, CarmoRomeiro e Bresciani (2015).

Estas constatações vão de encontro às evidências identificadas nas nove entrevistas realizadas, as quais descrevem que o MTE possui o maior programa de financiamento da operação de microcrédito no Brasil, com o uso de recursos do Fundo de Amparo ao Trabalhador (FAT) e da parcela dos depósitos à vista destinados ao microcrédito (BRASIL, 2003).

Os entrevistados apontaram que as IMFs também contam com doações de recursos públicos e privados. Entretanto, essas doações representam um baixo montante se comparadas aos empréstimos realizados para dar suporte à operação de oferta de microcrédito.

Emergem, na discussão, os bancos comerciais, como relevantes parceiros das IMFs que atuam no mercado de microfinanças brasileiro, os quais além de utilizarem recursos próprios operam como intermediadores de fundos do MTE. Segundo entrevistados, os bancos comerciais oferecem linhas de crédito específicas para entidades operadoras de microcrédito, com taxas de juros que atendem às normativas da legislação.

Registre-se que durante a aplicação das entrevistas, foram mencionados casos de bancos de desenvolvimento estaduais que possuem linhas específicas para a operação de microcrédito em sua região, como por exemplo a Agência de Fomento do Estado de Santa Catarina S/A (BADESC) e a Agência de Fomento do Estado da Bahia S/A (DESENBAHIA).

Paralelamente, outras instituições nacionais e internacionais foram identificadas como influenciadoras do mercado de microfinanças brasileiro na percepção de gestores, são elas:

○ Ministério da Justiça;

- Banco Central;

- Forolac - Foro Latinoamericano y del Caribe de Finanzas Rurales;

- FINRURAL Bolívia- La Asociación de Instituciones Financieras de Desarrollo;

o The MIX;

○ Citi Foundation;

- SEBRAE; 
- CAF - Banco de Desenvolvimento da América Latina;

- Universidades; e

○ Governos (Estaduais e Municipais).

O fluxo dos fundos e seus possíveis influenciadores estão diretamente relacionados com a configuração do mercado de microfinanças brasileiro e podem ser ilustrados por meio da figura 4.

Figura 4- O Fluxo de Fundos no Mercado de Microfinanças na Visão dos Entrevistados

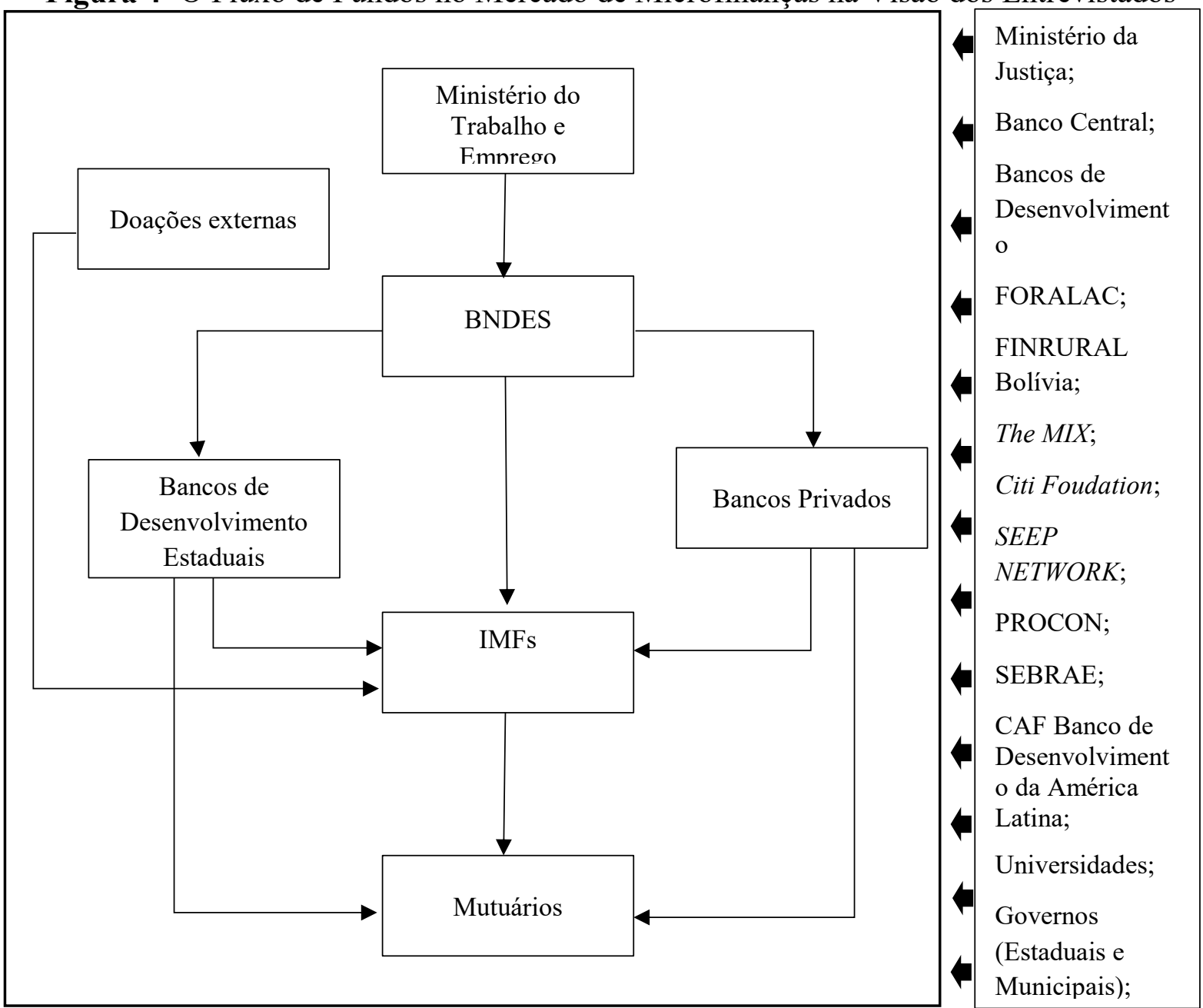

Fonte: Elaborado pelos autores.

Como pode ser contemplado pela figura anterior, os fundos chegam aos mutuários das microfinanças por intermédio de dois tipos de instituições: as que atuam apenas com a operação de microcrédito como sua atividade principal (IMFs) e as que o tem como secundário (Bancos de Desenvolvimento Estaduais e Bancos Privados).

Também pode ser evidenciado pela mesma figura, que as instituições ofertantes de microcrédito como atividade secundária repassam recursos para serem operados por IMFs e operam diretamente aos mutuários, atuando em duas linhas.

Este comportamento de bancos privados e bancos de desenvolvimento estaduais pode ser entendido ao considerar as afirmações de Stiglitz (1990). Os autores destacam a vantagem estratégica das IMFs frente a outros agentes do mercado de crédito, justamente por terem mais 
proximidade social com seus clientes. Assim, estas podem justificar a opção destes agentes econômicos em repassar os recursos para serem ofertados por instituições como as IMFs.

Cabe ressaltar, que um conjunto de organizações apoiadoras se encontram presentes no ambiente das microfinanças brasileiro, com base nas entrevistas. Estas podem atuar a partir da ação regulatória (Ministério da Justiça, Banco Central, Governos, Procon FORALAC), inovação tecnologia e processos de gestão (The Mix, Citi Foudation, Seep Network, Sebrae FINRURAL-Bolívia) e no desenvolvimento e ampliação das políticas e programas de microcrédito no setor (MTE, BNDES, Bancos de Desenvolvimento e Governos).

Por outro lado, estas constatações acerca do significativo número de organizações de suporte e reguladoras descrevem a necessidade de uma efetiva racionalização do setor de microfinanças por parte das IMFs, o que pode ser um fator estratégico para o resultado do desempenho destas instituições.

\section{Considerações Finais}

As discussões acerca do ambiente de gestão das instituições operadoras de microcrédito têm sido evidenciadas a partir do entendimento de sua importância como instrumento de suavização da pobreza em países em desenvolvimento.

Neste contexto, os resultados obtidos na presente pesquisa permitiram a consolidação de uma perspectiva do ambiente de gestão das instituições de microfinanças no Brasil, de forma a esclarecer o ordenamento do fluxo de fundos entre as organizações.

Por outro lado, pode-se ressaltar a presença constante do estado enquanto impulsionador do setor das microfinanças brasileiro, a partir do Programa Nacional do Microcrédito Produtivo Orientado (PNMPO), gerido pelo MTE com recursos do Fundo de Amparo ao Trabalhador e pelo suporte de instituições públicas federais, estaduais e municipais ao longo de grande parte do fluxo de fundos no setor.

Além do exposto, os bancos privados apresentaram-se como organizações que atuam em diferentes segmentos de transferência de recursos no mercado de microfinanças brasileiro, tanto para IMFs (com a finalidade exclusiva de subsidiar a operação de microcrédito destas organizações), quanto para mutuários.

Dentre as considerações da pesquisa evidencia-se a existência de um fluxo de informações, que paralelamente ao fluxo de fundos, tende a influenciar as escolhas estratégias das instituições, dado sua evidente densidade na governança do setor.

Adicionalmente cabe ressaltar que dada a dependência das IMFs de fundos oriundos do MTE e BNDES, suas estratégias institucionais são em partes induzidas a seguir as normativas dessas instituições, o que pode limitar seu desenvolvimento, como por exemplo taxa de juros limitada à $3 \%$ e a obrigatoriedade de acompanhamento do microcrédito ofertado (e os custos deste serviço).

Com relação ao ambiente de gestão das IMFs, espera-se que estas constatações possam auxiliar estrategicamente na tomada de decisão organizacionais, pois buscaram consolidar uma perspectiva do ambiente de microfinanças brasileiro.

Por fim, de modo a proporcionar norteamento para pesquisas futuras, pode-se destacar a existência de possíveis relações entre as organizações apoiadoras do setor de microfinanças brasileiro, como por exemplo com efeito nos processos de regulação ou na elaboração de políticas e programas de fomentos ao microcrédito. 


\section{Referências}

ADITTO, S.; GAN, C.; NARTEA, G. Economic risk analysis of alternative farming systems for smallholder farmers in central and north-east Thailand. International Journal of Social Economics, v. 41, n. 4, p. 294-320, 2014. DOI: https://doi.org/10.1108/IJSE-11-2012-0223

AL-MAMUN, A.; WAHAB, S. A.; MAZUMDER, M. N. H.; SU, Z. Empirical investigation on the impact of microcredit on women empowerment in urban Peninsular Malaysia. The Journal of Developing Areas, v. 48, n. 2, p. 287-306, 2014. DOI:

http://doi.org/10.1353/jda.2014.0030

ARMENDARIZ, B.; MORDUCH, J. The Economics of Microfinance , $2^{\text {a }}$ ed. Londres-UK: MIT, 2010.

AUGUSTO DE SOUZA, P. R.; CARMOROMEIRO, M.; BRESCIANI, L. P. Características del ofrecimiento de microcrédito en el programa brasileño de microcrédito en São Paulo.

Revista Científica Pensamiento y Gestión, n. 38, p. 77-94, 2015. Doi:

http://doi.org/10.14482/pege.38.7701

BANCO CENTRAL DO BRASIL - BACEN. Disponível em: < http://www.bacen.gov.br/>. Acesso: 16 mar. 2015.

BANCOSOL. Banco Sol - Produtos e Serviços Disponível em

$<$ https://www.bancosol.com.bo/secciones/productos-y-servicios $>$. Acesso em: 08 mar. 2015.

BARONE, F.; LIMA, P; DANTAS, V.; REZENDE, V. Introdução ao Microcrédito.

Brasília: Conselho da Comunidade Solidária, 2002.

BESLEY, T. Property rights and investment incentives: theory and evidence from ghana. Journal of Political Economy, v. 103, n. 5, p. 903-37, 1995.

BRASIL. Lei $\mathrm{n}^{\mathrm{o}} 10.735$ de 11 de setembro 2003. Dispõe sobre o direcionamento de depósitos à vista captados pelas instituições financeiras para operações de crédito destinadas à população de baixa renda e a microempreendedores, autoriza o Poder Executivo a instituir o PIPS, e dá outras providências. Diário Oficial da União, Brasília-DF, 2003.

BRASIL. Lei $\mathrm{n}^{\mathrm{o}} 11.110$ de 25 de abril de 2005. Institui o Programa Nacional de Microcrédito Produtivo Orientado - PNMPO e dá outras providências. Diário Oficial da União, BrasíliaDF, 2005.

CULL, R.; MORDUCH, J. Financial performance and outreach: a global analysis of leading microbanks. The Economic Journal, v. 117, n. 517, p. F107-F133, 2007. DOI:

http://doi.org/10.1111/j.1468-0297.2007.02017.x

DE SOUZA, P. A. R.; DA SILVA, V. G.; DA COSTA, S. R. Performance of microcredit banks: the offering process in the credit agents perspective. Acta Scientiarum. Human and Social Sciences, v. 39, n. 1, p. 1-9, 2017. 
GIANCOLI, B. P. O super endividamento do consumidor como hipótese de revisão dos contratos de crédito. Porto Alegre: Verbo Jurídico, 2008.

GONÇALVES, E. B.; GOUVÊA, M. A.; MANTOVANI, D. M. N. Análise de risco de crédito com o uso de regressão logística. Revista Contemporânea de Contabilidade, v. 10, n. 20, p. 139-160, 2013. DOI: http://dx.doi.org/10.5007/2175-8069.2013v10n20p139

HOQUE, M.; CHISHTY, M.; HALLOWAY, R. Commercialization and changes in capital structure in microfinance institutions. Managerial Finance, v. 37, n. 5, p. 414-25, 2011. DOI: https://doi.org/10.1108/03074351111126906

HUSAIN, J.; JIWANI, J. Microfinance: Effects of Contingent Incentive Programs on the Performance \& Productivity of Loan Officers. Journal of American Business Review, v. 1, n. 1, p. 141-47, 2012.

LATIFE, H. I. The Future of Microfinance: visioning the who, what, when, where, why, and how of microfinance expansion over the next 10 years. In: Microcredit Summit Campaign Commissioned Papers. Grameen Trust Bangladesh. Global Microcredit Summit 2006.

LOPES, A. L. V. Risco de crédito num contexto de crise. 2013, 100p. Dissertação (Mestrado em Contabilidade e Finanças). Instituto Superior de Contabilidade e Administração. Instituto Politécnico do Porto, Portugal, 2013.

MIRELES, R. D. V.; MEJÍA, L. Y.; RODRÍGUEZ, V. B. Implicaciones económico-sociales del microfinanciamiento para los micro y pequeños negocios del sector terciario del estado de coahuila (social economic implications of microfinance for micro and small commercial business of the state of coahuila). Revista Internacional Administración \& Finanzas, v. 7, n. 3, p. 113-123, 2014.

MIX. Microfinance Information eXchange Disponível em $<$ http://www.mixmarket.org/mfi/>. Acesso em: 08 nov. 2015.

MORDUCH, J. The microfinance promise. Journal of Economic Literature, v. 37, n. 4, p. 1569-1614, 2000.

PEREIRA, S. E.; FIGUEIREDO, A. S.; LOUREIRO, P. R. Avaliação do impacto da utilização de crédito, da educação e da escolha do canal de comercialização na horticultura: caso do núcleo rural do Distrito Federal. Revista de Economia e Sociologia Rural, v. 44, n. 4, p. 773-99, 2006. DOI: http://dx.doi.org/10.1590/S0103-20032006000400008

PEREIRA, S.; MOURAO, P. Why does the microcredit borrowing rate differ across countries? A cross-country study. International Journal of Social Economics, v. 39, n. 8, p. 536-50, 2012. DOI: https://doi.org/10.1108/03068291211238428

POLLINGER, J. J.; OUTHWAITE, J.; CORDERO-GUZMÁN, H. The Question of Sustainability for Microfinance Institutions. Journal of Small Business Management, v. 45, n. 1, p. 23-41, 2007. DOI: http://doi.org/10.1111/j.1540-627X.2007.00196.x 
RUSCHEINSKY, A.; MENDIZÁBAL, D. M. Política social, paradigma de bem-estar e prática política: análise comparativa de programas de transferências condicionadas. Revista Katálysis, v. 17, n. 1, p. 31-40, 2014. DOI: http://dx.doi.org/10.1590/S141449802014000100004

SANFELIU, C. B.; ROYO, R. C.; CLEMENTE, I. M. Measuring performance of social and non-profit Microfinance Institutions (MFIs): An application of multicriterion methodology. Mathematical and Computer Modelling, v. 57, n. 7, p. 1671-78, 2013. DOI: https://doi.org/10.1016/j.mcm.2011.11.010

SCHRICKEL, W. K. Análise de crédito: concessão e gerência de empréstimos. São Paulo: Atlas, 1995.

SCHUMPETER, J. A. Teoria do desenvolvimento econômico: Uma investigação sobre lucros. São Paulo: Nova Cultural, 1997.

SOUZA, P. A. R. O desempenho das instituições de microfinanças no Brasil: identificação de fatores de influência. 2015, 235p. Tese (Doutorado em Administração). Programa de PósGraduação em Administração. Universidade Municipal de São Caetano do Sul. São Paulo, 2015.

STIGLITZ, J. E. Monitoramento Peer e mercados de crédito. A análise econômica do Banco Mundial, v.4, n. 3, p. 351-66, 1990.

TRIVIÑOS, A. N. S. Introdução à pesquisa em ciências sociais: a pesquisa qualitativa em educação. São Paulo: Atlas, 1987.

VERGARA, S. C. Métodos de pesquisa em administração. São Paulo: Atlas, 2012.

VIEIRA, E. S.; PINHO, C. C.; OLIVEIRA, D. A Concessão de Crédito Comercial e o Financiamento dos Clientes: evidência nas empresas portuguesas. Revista Universo Contábil, v. 9, n. 4, p. 144-56, 2013. DOI: http://doi.org/10.4270/RUC.2013435

WILBERT, M. D.; SERRANO, A. L. M.; GONÇALVES, R. S.; ALVES, L. S. Redução do imposto sobre produtos industrializados e seu efeito sobre a venda de automóveis no Brasil: uma análise do período de 2006 a 2013. Revista Contemporânea de Contabilidade, v. 11, n. 24, p. 107-124, 2014. DOI: https://doi.org/10.5007/2175-8069.2014v11n24p107

XAVIER, B. D. J. Os Principais Aspectos para Análise, Concessão e Administração do Crédito. Maringá Management, v. 9, n. 1, p. 37-43, 2012.

* Os autores desta pesquisa agradecem ao auxílio financeiro concedido pela CAPES (Coordenação de Aperfeiçoamento de Pessoal Docente), a partir do Programa de Doutorado Sanduíche no Exterior (PDSE), o qual deu suporte ao desenvolvimento desta pesquisa e as considerações do comitê editorial da Revista Contemporânea de Contabilidade. 